\title{
An Invitation to Explore Unexamined Shifts and Variety in the Meanings of Genotype and Phenotype, and Their Distinction
}

\author{
Peter J. Taylor*
}

\begin{abstract}
Noting minimal philosophical attention to the shift of the meanings of "genotype" and "phenotype," and their distinction, as well as to the variety of meanings that have co-existed over the last hundred years, this note invites readers to join in exploring the implications of shifts that have been left unexamined.
\end{abstract}

\section{Keywords}

abstraction $\bullet$ breeding experiments $\bullet$ classes $\bullet$ history $\bullet$ lacuna $\bullet$ method

The predominant current-day meaning of "genotype" is some relevant part of the DNA passed to the organism by its parents. The "phenotype" is the physical and behavioral traits of the organism, for example, size and shape, metabolic activities, and patterns of movement. However, the original meanings of "genotype" and "phenotype" and of the distinction between them, as given by Wilhelm Johannsen (1911), were quite different. In brief, for Johannsen, "type" connotes a class. The phenotype, consisting of a group of organisms "distinguishable by direct inspection or ... by finer methods of measuring or description," is used to identify the genotype as a class of organisms that shares some unidentified constituents that are stable from generation to generation (134). As I worked with Richard Lewontin to prepare the latest revision of the entry on the genotype-phenotype distinction for the Stanford Encyclopedia of Philosophy (Taylor and Lewontin 2017), we found minimal philosophical attention to the shift of the terms' meanings as well as to the variety of meanings that have co-existed over the last hundred years (but see Roll-Hansen 2014). Philosophical discussion mostly now takes the predominant current meaning as given, focusing instead on questions about the genotype-phenotype relationship.

In sharing this observation as a note, my hope is that the lacuna strikes other Philosophy, Theory, and Practice in Biology readers as worth exploring. The point is not that we need to return to Johannsen's original definitions, but that philosophers could be troubled by shifts that have been left unexamined. Indeed, it is not necessary to demonstrate problems with the predominant

${ }^{*}$ Science in a Changing World graduate program, University of Massachusetts, Boston, MA 02125, USA peter.taylor@umb.edu 
current meanings before suggesting that a lacuna could provide a window into interesting conceptual and historical issues. (While it is not in its own right a problem, readers might find it curious that most people these days use the terms "genotype" and "phenotype" synonymously with, respectively, "DNA" and "trait"-why do we not simply use the latter terms?) Perhaps some readers need the issues to be teased out for them before they ascribe any significance to the lack of attention to the shift of the terms' meanings and to the co-existing variety of meanings. That response is understandable; for you, this note can be viewed as a promissory note on work that might not, however, see the light of day for some time given my other commitments. Readers who, however, are intrigued by the observation might be happy to share the work by taking up one of the following possible points of entry. (Listing these should also serve to indicate that there is more space to explore than can be covered by any one person or field.)

- Notwithstanding his definition of "phenotype," no method is discussed in Johannsen (1911) to divide a natural varying population into phenotypes, let alone identify a genotypeas-class in such populations. It is in the restricted realm of his inbred lines of beans that identifying genotypes from phenotypes is possible, albeit not reliably if a phenotype includes a mix of inbred lines.

- What are the implications of conceptualizing heredity on the basis of breeding experiments? Of course, from Mendelian experiments to modern biotechnology we have seen a progressively increasing capacity to control conditions and harness crossbred and genetically engineered organisms to produce desired product. However, biological theory is meant-is it not? - to apply also to naturally variable populations.

- "Type" also connotes an abstraction away from the full set of observed characteristics. What then is to be accentuated and what de-emphasized about a genotype and phenotype, either as DNA and traits or as classes? And how-by what concepts, methods, and models - is what has been de-emphasized to be brought back and reintegrated into the scientific account?

- What illumination of conceptual issues can be drawn from the rich social and economic history of heredity, where concrete cases abound concerning the control of biological materials for production and breeding-dating from well before the genotype-phenotype distinction through to present-day biotechnology? (See Müller-Wille et al. 2008; Deichmann et al. 2014; Müller-Wille and Brandt 2016; and references cited therein.)

\section{Literature cited}

Deichmann, Ute, Michel Morange, and Anthony S. Travis. 2014. "Special Issue: The Changing Concept of the Gene: Recurrent Debates on the Causal Role of Genes." Perspectives in Biology and Medicine 57 (1): 4-178.

Johannsen, W. 1911. “The Genotype Conception of Heredity.” The American Naturalist 45: 129-159.

Müller-Wille, Staffan. 2008. "Leaving Inheritance Behind: Wilhelm Johannsen and the Politics of Mendelism." In A Cultural History of Heredity IV: Heredity in the Century of the Gene, edited by Staffan Müller-Wille, Hans-Jörg Rheinberger, and John Dupré, 7-18. Berlin: Max Planck Institute for the History of Science.

Müller-Wille, Staffan, and Christina Brandt, eds. 2016. Heredity Explored: Between Public Domain and Experimental Science, 1850-1930. Cambridge, MA: MIT Press. 
Roll-Hansen, Nils. 2014. "The Holist Tradition in Twentieth Century Genetics: Wilhelm Johannsen's Genotype Concept.” Journal of Physiology 592 (11): 2431-2438.

Taylor, Peter J., and Richard C. Lewontin. 2017. “The Genotype/Phenotype Distinction.” In The Stanford Encyclopedia of Philosophy, edited by Edward N. Zalta. Palo Alto, CA. https://plato.stanford. edu/entries/genotype-phenotype/

(C) 2018 Author(s)

This is an open-access article distributed under the terms of the Creative Commons AttributionNonCommercial-NoDerivatives 4.0 International license, which permits anyone to download, copy, distribute, or display the full text without asking for permission, provided that the creator(s) are given full credit, no derivative works are created, and the work is not used for commercial purposes.

ISSN 2475-3025 